\title{
Predisposição para Doação de Medula Óssea à luz da Teoria do Comportamento Planejado
}

\author{
Bone Marrow Donation Intentions in light of the Theory of Planned Behavior
}

\author{
Pedro Coelho \\ Universidade Federal do Ceará - UFC - Brasil \\ pedro.coelho@ufob.edu.br \\ ORCID: https://orcid.org/0000-0002-3376-3552 \\ Iveltyma Ibiapina \\ Universidade Federal do Ceará - UFC - Brasil \\ iveltyma.ibiapina@gmail.com \\ ORCID: https://orcid.org/0000-0001-8062-8700 \\ Áurio Lúcio Leocádio da Silva \\ Universidade Federal do Ceará - UFC - Brasil \\ aurioleocadio42@gmail.com \\ ORCID: https://orcid.org/0000-0003-3175-3382 \\ Daniel Barboza Guimarães \\ Universidade Federal do Ceará - UFC - Brasil \\ barbozadan@hotmail.com \\ ORCID: https://orcid.org/0000-0001-6966-7194
}

Submetido em 31/07/2018; Aprovado em 07/09/2018

\section{Resumo}

A doação de órgãos é uma temática que vem sendo explorada por pesquisadores de marketing nos últimos anos. Trata-se de um assunto socialmente relevante, em função dos desafios enfrentados por indivíduos que precisam de doação de órgãos no Brasil. A chance de encontrar medula compatível no país é de uma em cem mil. Diante disso, esta pesquisa tem o objetivo de analisar os fatores que antecedem a intenção dos indivíduos em realizar o cadastro de doação de medula óssea. Utilizou-se a Teoria do Comportamento Planejado como suporte ao desenvolvimento de um modelo conceitual, que foi testado empiricamente por meio da aplicação de 335 questionários. Os resultados da Modelagem de Equações Estruturais apontam que a atitude e o controle comportamental percebidos possuem relação positiva com a intenção comportamental de realizar o cadastro para doação de medula. Também foi constatado que as pessoas que possuem informações sobre o processo de doação de órgãos esboçam uma atitude positiva para a realização do cadastro. Entretanto, a norma subjetiva não possui relação significativa com esta intenção comportamental. Com base no modelo ajustado, constatou-se que as campanhas de marketing social devem, além de informar os potenciais doadores sobre o processo de doação, reforçar que esta ação é essencial para a saúde dos pacientes que precisam do transplante.

Palavras-chave: Teoria do Comportamento Planejado. Doação de Órgãos. Marketing Social. Doação de Medula Óssea.

\begin{abstract}
Organ donation is a topic that has been explored by marketing researchers in recent years. This is a socially relevant issue, due to the challenges faced by individuals who need organ donation in Brazil. The chance of finding compatible marrow in the country is one in a hundred thousand. In this sense, this research has the objective of analyzing the factors that precede the intention of the individuals to perform the registration of donation bone marrow. The Theory of Planned Behavior was used to support the development of a conceptual model, which was empirically tested through the application of 335 questionnaires. The results of the Structural Equation Modeling show that attitude and perceived behavioral control have a positive relation with the behavioral intention of performing the registration
\end{abstract}


for donation bone marrow. It has also been found that people who have information about the organ donation process outline a positive attitude towards the registration. However, the subjective norm has no significant relation with this behavioral intention. Based on the adjusted model, it was found that social marketing campaigns should not only inform potential donors about the donation process, but also reinforce that this action is essential for the patients who need the transplant.

Keywords: Theory of Planned Behavior. Organ Donation. Social Marketing. Donating Bone Marrow.

\section{Introdução}

Estudos recentes de marketing vêm abordando temáticas socialmente relevantes, como o comportamento de consumo de pessoas com deficiência (Faria, 2015) e o consumo de produtos orgânicos (Brandão, 2016). Outras pesquisas retrataram o processo de doação de sangue (Barboza \& Costa, 2014) e doação de órgãos (Rezende et al., 2015), porém, a motivação para a doação de medula óssea é um objeto de estudo inexplorado na área.

A medula óssea é um tecido que ocupa o interior dos ossos, sendo conhecido popularmente por "tutano". Na medula óssea são produzidos os componentes do sangue: glóbulos vermelhos, plaquetas e glóbulos brancos. Dessa forma, o transplante de medula óssea é recomendado a pacientes com doenças que afetam as células do sangue, como leucemias. Trata-se da substituição da medula óssea doente por uma saudável. Com isso, o organismo do paciente transplantado passa a produzir novas células da medula óssea e do sangue (Instituto Nacional de Câncer [INCA], 2012).

No Brasil, a doação de órgãos é regulamentada pela Lei no 9.434, de 4 de fevereiro de 1997. Apesar da legislação pertinente e da atuação de diversos órgãos de saúde associados à causa, o que se identifica no país é uma elevada demanda de pessoas à espera de um doador de órgãos compatível e, por outro lado, uma baixa oferta de possíveis doadores potenciais. Especificamente sobre a medula óssea, a chance de se encontrar medula compatível no país é de uma em cem mil (Associação Brasileira de Transplantes de Órgãos [ABTO], 2018). Mundialmente, há uma confirmação da doença maligna dos glóbulos brancos (leucemias) que excede a 120 mil casos por ano.

Uma vez definida a opção pelo transplante, inicia-se a busca pela identificação do doador de medula óssea compatível, que pode ser proveniente do núcleo familiar (doador relacionado) ou disponibilizado mediante a doação de voluntários (doadores não relacionados). Por essa razão, quanto maior o número de doadores cadastrados, maiores as chances dos pacientes (INCA, 2012).

Em um primeiro momento, a pessoa só faz um cadastro como doador e passa a fazer parte do Registro Nacional de Doadores Voluntários de Medula Óssea, o REDOME. O doador só será convocado para fazer a doação se for verificada compatibilidade com algum paciente. Contudo, o número de pessoas cadastradas é insuficiente, diminuindo a probabilidade de sucesso do tratamento (ABT0, 2018).

Diante disso, este estudo tem o objetivo de analisar os fatores que antecedem a intenção dos indivíduos em realizar o cadastro de doação de medula óssea. Para alcançar o seu objetivo, optou-se por investigar este objeto de estudo a partir da Teoria do Comportamento Planejado (TCP). Tal teoria considera que as pessoas utilizam as informações que estão disponíveis a eles para considerar as consequências de suas ações antes de decidirem se devem ou não se comportar de determinada forma (Ajzen, 2002) e será discutida em seguida.

\section{Referencial Teórico}

A Teoria do Comportamento Planejado (TCP), proposta por Ajzen (1991), é uma extensão da Teoria da Ação Racional, introduzida por Fishbein e Ajzen (1975). 0 modelo da TCP é capaz de prever com maior precisão e explicar o comportamento humano. Essa teoria parte da suposição que todas as pessoas tomam suas decisões de forma extremamente racional, além de considerar que os indivíduos utilizam minuciosamente as informações que estão disponíveis a eles para considerar as consequências de suas ações antes de decidirem se devem ou não se comportar de determinada forma (Ajzen, 2002).

A TCP é bem utilizada no campo da psicologia, especialmente para investigar os fatores preditores de comportamentos, como a amamentação materna e a doação de órgãos (Moutinho \& Roazzi, 2010). Dentro do campo da saúde, essa teoria é amplamente utilizada e tem mostrado uma forte utilidade preditiva para muitos comportamentos realizados, por exemplo, intenção de realizar dietas e atividades físicas (Goecking, 2006), uso de condons por adolescentes (Matos, Veiga, \& Lima, 2008) e o consumo de drogas (Conner \& Mcmillan, 1999).

$\mathrm{Na}$ área de marketing, essa teoria já serviu de base para verificar os determinantes de variados 
tipos de comportamentos, relativos ao consumo de produtos orgânicos (Hoppe et al, 2012), à escolha da universidade no ensino superior privado (Sousa et al., 2013), à escolha do não uso das sacolas de plástico (Matos, 2013) e ao consumo de cosméticos ecológicos (Veiga, Santos, \& Lacerda, 2006), por exemplo. Contudo, não se verificou a utilização dessa teoria para analisar comportamentos realizados quanto à doação de medula óssea.

0 diagnóstico instaura um momento de crise na medida em que um novo conflito se instala, gerando inquietação e insegurança, tanto no paciente como nos familiares: submeter-se ou não ao TMO. Esse questionamento se dá, principalmente, em virtude das peculiaridades da terapêutica - o transplante é visto como tratamento salvador e, ao mesmo tempo, um tratamento ameaçador, devido aos riscos associados. 0 doador é internado na véspera do procedimento e permanecerá hospitalizado por dois a três dias. 0 volume total da medula retirado, em média, aproxima-se de um litro. Depois de concluído o procedimento, o doador, frequentemente, necessitará da autotransfusão de sangue. Não obstante ao fato de ser um procedimento invasivo, normalmente não deixa sequelas físicas (OliveiraCardoso et al., 2010).

$\mathrm{Na}$ doação relacionada, o que motiva o doador é o fato de o indivíduo ser colocado, potencialmente, como o salvador de uma vida. Nesse contexto, sublinha-se que a doação fica condicionada e, só se concretizará, após a autorização do cônjuge ou parente, maior de idade, obedecida a linha sucessória, reta ou colateral, até o segundo grau inclusive, firmada em documento subscrito por duas testemunhas presentes à verificação da morte e, caso seja realizada, poderá acontecer com ou sem o consentimento do doador (Doró \& Pasquini, 2000).

Ressalta-se ainda que a realização do transplante é condicionada a diferentes variáveis, tais como: saúde do doador, que deve ser comprovada por meio de exames médicos, para evitar que o receptor do órgão seja contaminado por algum tipo de doença, complicando assim, seu quadro de saúde; a compatibilidade do doador versus receptor e ainda atender todas as cláusulas estabelecidas pela Legislação Brasileira sobre doação de órgãos humanos (Lei no 9.434, 1997).

Dentre os aspectos relevantes para que um indivíduo se torne um doador, destaca-se a qualidade das informações que a pessoa possui sobre os procedimentos da doação de medula óssea. A informação é um fator importante para que o indivíduo se torne um doador, pois, através do conhecimento sobre os procedimentos e consequências do seu comportamento, o indivíduo consegue pensar bem antes de ter esse comportamento (Beerli-Palacio \& Martín-Santana, 2009). Analogamente, acredita-se que tal fator seja preponderante para que o indivíduo se cadastre como doador de medula óssea. Esse entendimento constitui as três primeiras hipóteses do presente estudo, enunciadas a seguir:

H1 - A informação influencia positivamente a atitude.

H2 - A informação influencia positivamente a norma subjetiva.

H3 - A informação influencia positivamente o controle comportamental percebido.

A variável informação foi adicionada por ter sido verificada em estudos sobre doação de sangue (Barboza \& Costa, 2014; Pereira et al., 2016). Considera-se que o comportamento de um indivíduo pode ser definido como uma função de uma dada intenção comportamental e de fatores situacionais que não puderam ser previstos pelo indivíduo no momento em que ele expressou sua intenção (Sheet, 1974).

A TCP postula três constructos determinantes da intenção que são conceitualmente independentes. A primeira é a atitude em relação ao comportamento, ela refere-se ao grau de avaliação, ou avaliação favorável ou desfavorável, que uma pessoa tem do comportamento em questão. A atitude positiva predispõe a aproximação do indivíduo de realizar o comportamento, enquanto uma atitude negativa pode levar ao afastamento do comportamento. Assim, as atitudes ajudam a ter uma ideia estável da realidade em que os indivíduos se encontram, protegendo-os de situações desagradáveis (Ajzen, 1988). Caso a atitude do indivíduo seja favorável à doação de medula óssea, a probabilidade desse indivíduo se cadastrar como doador de medula óssea é maior (Lemmens et al., 2009), logo, a quarta hipótese ficou definida como:

H4 - A atitude das pessoas influencia positivamente a intenção.

O segundo é um fator social denominado norma subjetiva, que se refere à pressão social percebida para executar ou não o comportamento A Norma Subjetiva é determinada com base na percepção do agente em relação à opinião de cada pessoa que é relevante ou referente para ele, formando o conjunto denominado de crenças normativas devido à sua natureza social. Ela reflete a percepção da pressão 
social que os indivíduos podem sentir para executar o comportamento, estando ligada também à importância do indivíduo no grupo, ou seja, aprovação ou desaprovação do comportamento pelos outros (Ajzen \& Fishbein, 1970). Levando em consideração esse aspecto, a percepção da sociedade que o indivíduo tem sobre o cadastro para a doação de medula óssea deve influenciar na decisão de comportamento dele (Silva et al. 2016). A partir disso, a hipótese a seguir foi definida:

H5 - A norma subjetiva influencia positivamente a intenção.

0 terceiro antecedente de intenção é o grau de controle comportamental percebido, que se refere à facilidade ou à dificuldade percebida para realizar o comportamento, através de uma suposta reflexão de uma experiência passada, bem como impedimentos e obstáculos pressupostos. Ele é a capacidade de realizar uma intenção, se o indivíduo tiver recursos e oportunidades para realizar a ação. 0 controle comportamental percebido pode atuar juntamente com a intenção ou pode atuar diretamente na realização comportamental (Ajzen, 2002). No cadastro de doação de medula óssea, caso o indivíduo tenha essa percepção de controle, esse controle pode ser um fator positivo para o cadastro (Santos \& Massarollo, 2005; Shaz et al., 2009). Sabendo disso, a hipótese foi definida como:

H6 - O controle comportamental percebido influencia positivamente a intenção.

Já as intenções comportamentais podem ser compreendidas como um resumo da motivação necessária para desempenhar um comportamento particular, refletindo uma decisão do indivíduo de seguir um curso de ação, bem como um índice sobre o quanto uma pessoa estaria disposta a tentar desempenhar um comportamento (Fishben \& Ajzen, 1975). Ela é a indicação de quanto de esforço deve ser utilizado ordenadamente para realizar um comportamento, sendo influenciado por três componentes: a atitude, a norma subjetiva e o controle comportamental percebido. Considerando que também a influência das informações que os indivíduos dispõem sobre a doação na intenção de doação de órgãos, conforme achados de Silva et al. (2016), foi definida a última hipótese:

H7 - A informação influencia positivamente a intenção.

A partir da revisão da literatura sobre a temática, buscou-se definir um modelo conceitual para analisar os antecedentes da doação de medula óssea à luz da Teoria do Comportamento Planejado. 0 modelo utilizado nesta pesquisa é apresentado na Figura 1.

Figura 1 - Modelo conceitual da pesquisa

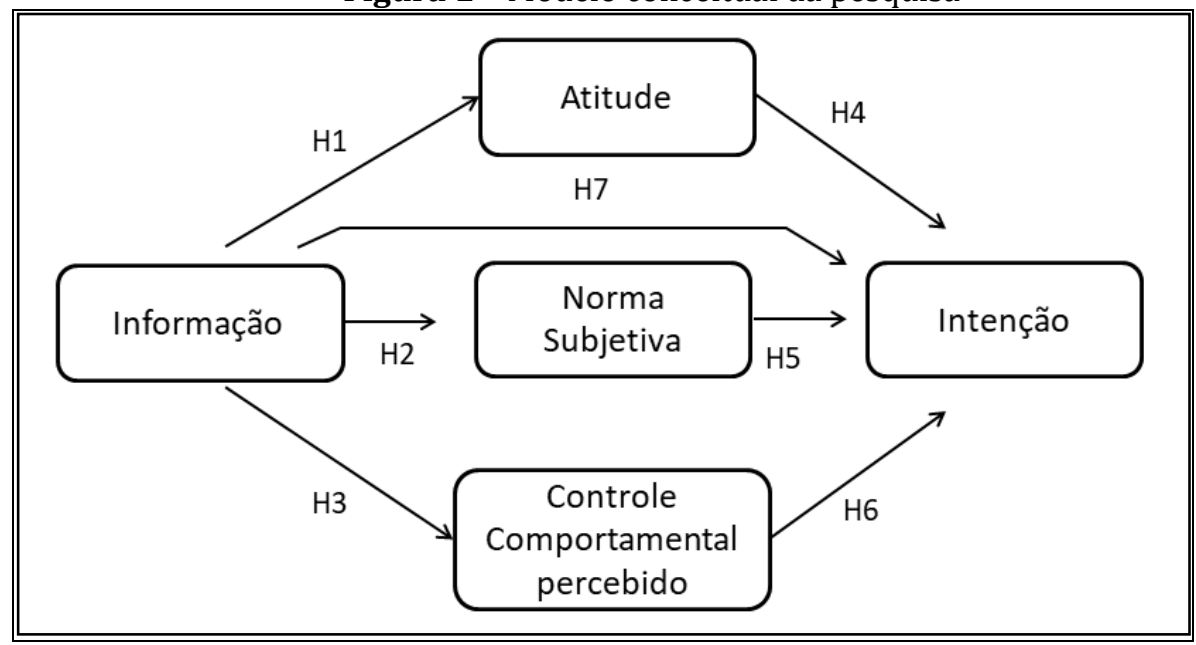

Fonte: Elaborado pelos autores (2018).

No modelo acima, sete hipóteses foram elencadas. Este estudo, portanto, busca verificar a validade das hipóteses supracitadas sobre a intenção de indivíduos realizarem o cadastro como doadores de medula óssea. Dando prosseguimento, a próxima seção apresentará os procedimentos metodológicos adotados que permitirão a validação ou não dessas hipóteses.

\section{Método}

O estudo buscou testar a influência da atitude, das crenças normativas, do controle comportamental percebido e da informação sobre a intenção, ou não intenção, de indivíduos se 
cadastrarem no banco nacional de doadores de medula óssea. Para tanto, adotou-se um método de pesquisa quantitativo, que é o requerido para testes de modelos.

Na etapa empírica do estudo foi aplicado um questionário com escalas validadas que tratavam dos constructos informação, atitude, norma subjetiva, controle percebido e intenção. 0 instrumento de coleta de dados foi respondido por 335 respondentes. Os dados obtidos foram analisados por meio da Modelagem de Equações Estruturais. Assim, as decisões relativas à coleta dos dados e aos procedimentos de análise serão descritas a seguir.

\subsection{Coleta de Dados}

Quanto à mensuração dos construtos, foram selecionadas escalas previamente utilizadas em outros estudos. 0 constructo informação foi obtido a partir do estudo de Beerli-Palacio e Martín-Santana (2009). Já as escalas que trataram dos constructos da TCP foram adaptadas de outros estudos relacionados à doação de sangue (Lemmens et al., 2009; Shaz et al., 2009). Esses constructos foram mencionados de outras formas, porém, quando são trazidos para a realidade da TCP, se encaixam perfeitamente dentro da teoria.

As escalas foram adaptadas de duas formas. Primeiramente, foi realizada a tradução para a língua portuguesa, na qual os itens foram apresentados como afirmações, sendo usada uma escala de verificação de 10 pontos para averiguação de concordância (escala de Likert).

A segunda adaptação foi em relação ao contexto do estudo, os estudos anteriores eram relacionados à doação de sangue e o presente trabalho refere-se ao cadastro de doador de medula óssea. Os construtos, as variáveis e os autores estão elencados no quadro 1.

Quadro 1 - Construtos e variáveis da pesquisa

\begin{tabular}{|c|c|c|c|}
\hline Constructo & & Variável & Autor \\
\hline \multirow{4}{*}{ Informação } & INF1 & $\begin{array}{l}\text { Conheço os requisitos para ser um doador, portanto, sei que posso (ou não) } \\
\text { realizar o cadastro como doador de medula óssea. }\end{array}$ & \multirow{4}{*}{$\begin{array}{c}\text { (Beerli-Palacio \& } \\
\text { Martín-Santana, } \\
\text { 2009) }\end{array}$} \\
\hline & INF2 & Entendo bem onde posso me cadastrar para ser um doador de medula óssea & \\
\hline & INF3 & $\begin{array}{l}\text { Eu conheço profundamente os benefícios de realizar o cadastro como doador } \\
\text { de medula óssea. }\end{array}$ & \\
\hline & INF4 & $\begin{array}{l}\text { Eu sei quais as doenças que restringem a realização do cadastro como } \\
\text { doador de medula óssea. }\end{array}$ & \\
\hline \multirow{3}{*}{ Atitude } & ATI1 & Eu gosto da ideia de realizar o cadastro como doador de medula óssea. & \multirow{3}{*}{$\begin{array}{l}\text { (Lemmens et al., } \\
2009 \text { ) }\end{array}$} \\
\hline & ATI2 & Realizar o cadastro para doar medula óssea é uma possibilidade atrativa & \\
\hline & ATI3 & $\begin{array}{l}\text { Eu tenho uma atitude favorável à ideia de realizar o cadastro como doador de } \\
\text { medula óssea }\end{array}$ & \\
\hline \multirow{5}{*}{$\begin{array}{l}\text { Norma } \\
\text { subjetiva }\end{array}$} & SUB1 & $\begin{array}{l}\text { A maioria das pessoas importantes para mim acredita que eu devo realizar o } \\
\text { cadastro como doador de medula óssea }\end{array}$ & \multirow{5}{*}{ (Shaz et al., 2009) } \\
\hline & SUB2 & $\begin{array}{l}\text { As pessoas que eu gosto querem que eu realize o cadastro como doador de } \\
\text { medula óssea }\end{array}$ & \\
\hline & SUB3 & $\begin{array}{l}\text { Pessoas que possuem opiniões que eu concordo acreditam que eu devo } \\
\text { realizar o cadastro como doador de medula óssea }\end{array}$ & \\
\hline & SUB4 & $\begin{array}{l}\text { A opinião dos meus amigos influencia minha decisão de me cadastrar como } \\
\text { doador de medula óssea }\end{array}$ & \\
\hline & SUB5 & $\begin{array}{l}\text { A opinião dos meus familiares influencia minha decisão de realizar o cadastro } \\
\text { como doador de medula óssea }\end{array}$ & \\
\hline \multirow{5}{*}{$\begin{array}{l}\text { Controle } \\
\text { percebido }\end{array}$} & CON1 & $\begin{array}{l}\text { Acredito que eu estou apto a realizar o cadastro como doador de medula } \\
\text { óssea }\end{array}$ & \multirow{5}{*}{$\begin{array}{c}\text { (Beerli-Palacio \& } \\
\text { Martín-Santana, } \\
\text { 2009) }\end{array}$} \\
\hline & CON2 & $\begin{array}{l}\text { Eu me vejo como um indivíduo que irá realizar o cadastro como doador de } \\
\text { medula óssea no futuro }\end{array}$ & \\
\hline & CON3 & Eu tenho tempo para realizar o cadastro como doador de medula óssea & \\
\hline & CON4 & $\begin{array}{l}\text { Acredito que eu tenho recursos para realizar o cadastro como doador de } \\
\text { medula óssea }\end{array}$ & \\
\hline & CON5 & Realizar o cadastro como doador de medula óssea é algo viável para mim & \\
\hline \multirow{3}{*}{ Intenção } & INT1 & Pretendo definitivamente realizar o cadastro como doador de medula óssea & \multirow{3}{*}{$\begin{array}{l}\text { (Lemmens et al., } \\
\text { 2009) }\end{array}$} \\
\hline & INT2 & $\begin{array}{l}\text { Sou uma pessoa que possui a intenção de realizar o cadastro como doador de } \\
\text { medula óssea }\end{array}$ & \\
\hline & INT3 & Creio que um dia vou realizar o cadastro como doador de medula óssea & \\
\hline
\end{tabular}

Fonte: Elaborado pelos autores (2018).

A aplicação dos questionários foi realizada de modo virtual, através da divulgação pelos autores, em redes sociais. Vale ressaltar que, em nenhum momento, o questionário aqui utilizado foi divulgado 
em grupos específicos de doadores de medula óssea, para minimizar a ocorrência de um possível viés no estudo. 0 questionário ficou disponível para resposta do dia 08 ao dia 15 de dezembro de 2017, e, neste período, foram obtidas 335 respostas.

\subsection{Análise de Dados}

Com o objetivo de testar o modelo teórico apresentado na Figura 1, optou-se pela utilização da Modelagem de Equações Estruturais (MEE). Como recomenda a literatura (Hair et al., 2014), primeiramente foram verificados os pressupostos para a aplicação desta técnica. A ausência de multicolinearidade foi verificada por meio do cálculo do Fator de Inflação da Variância (VIF). Mesmo não existindo um valor ideal para o teste, considerou-se, baseado na literatura, que VIFs menores do que 10 indicariam ausência de relações lineares entre as variáveis independentes (Hair et al., 2014).

A homocedasticidade foi verificada por meio do cálculo de Levene e, finalmente, a hipótese de normalidade das variáveis dependentes utilizadas no modelo foi verificada por meio do teste de Kolmogorov-Smirnov, que é o teste alternativo ao teste de $\mathrm{W}$ de Shapiro para amostras com mais de 30 observações (Hair et al., 2014). Após a realização desses testes, procedeu-se com a MEE, seguindo a metodologia proposta por Ringle, Silva e Bido (2014), com estimação dos mínimos quadrados parciais.

Para a validade convergente, buscou-se identificar cargas superiores $(\lambda)$ a 0,60 entre os itens e o construto mensurado, e, para validade convergente, exigiu-se que a raiz quadrada da AVE (Average Variance Extracted) do construto fosse maior que a correlação deste com os outros construtos do modelo. Verificou-se também a consistência interna da escala, por meio do Alpha de Cronbach (superior a 0,60), a confiabilidade composta (superior a 0,60) e a própria AVE (superior a 0,50), como recomendado pela literatura (Hair et al., 2014). Os procedimentos foram realizados com o auxílio do software SmartPLS 2.0M3 e os resultados serão discutidos na seção seguinte.

\section{Discussão de Resultados}

Conforme mencionado anteriormente, a amostra final válida foi composta por 335 respondentes. Observou-se uma maior predominância de respondentes do gênero feminino, representando $70,2 \%$ da amostra. A maior faixa etária dos respondentes foi a classe correspondente a 24 a 29 anos. Em relação à renda familiar, houve duas faixas que se destacaram: entre dois e cinco salários mínimos, com 37,8\%, e acima de 5 salários mínimos, com 39,5\% dos respondentes. Em relação à escolaridade, o nível que mais se destacou foi o de pessoas com ensino superior completo, com $44,5 \%$ dos respondentes.

Para verificar os pressupostos da realização da MEE, foi realizado inicialmente o Teste de Levene. Os resultados apresentaram indicadores não significativos, ao mesmo tempo em que os VIFs indicaram a ausência da multicolinearidade. Por outro lado, o teste $\mathrm{Z}$ de Kolmogorov-Smirnov apresentou indicadores significativos, sendo possível concluir que a amostra não é aderente a uma distribuição normal. Dessa forma, optou-se por utilizar o método de mínimos quadrados parciais, pois modelos baseados na matriz de covariância exigem que a distribuição seja normal, por se caracterizarem como testes paramétricos (Hair et al., 2014).

Tabela 1 - Valores iniciais da qualidade de ajuste do modelo MEE

\begin{tabular}{cclcc}
\hline Construto & AVE & $\begin{array}{c}\text { Confiabilidade } \\
\text { Composta }\end{array}$ & $\mathbf{R}^{2}$ & $\boldsymbol{\alpha}$ \\
\hline ATI & 0,8285 & 0,9354 & 0,3928 & 0,8965 \\
CCP & 0,6750 & 0,9113 & 0,4907 & 0,8769 \\
INF & 0,7288 & 0,9148 & & 0,8756 \\
INT & 0,8881 & 0,9597 & 0,8059 & 0,9368 \\
NOR & 0,5227 & 0,7820 & 0,1928 & 0,7654 \\
\hline
\end{tabular}

Fonte: Elaborado pelos autores (2018).

Múltiplos critérios devem ser empregados para avaliar, de modo geral, o ajustamento do modelo teórico, uma vez que não existe consenso sobre um único índice ou padrão (Hair et al., 2014). 0 primeiro critério a ser observado nos modelos de mensuração são as Validades Convergentes, obtidas pelas observações das Variâncias Médias Extraídas (AVEs). Utilizou-se o critério de Fornell e Larcker (Henseler et al., 2009), sendo assim, os valores das AVEs devem ser maiores que 0,50 (AVE >0,50). A AVE é a porção dos dados (nas respectivas variáveis) que é explicada por cada um dos constructos ou VL, respectivos aos seus conjuntos de variáveis, ou quanto, em média, as variáveis se correlacionam positivamente com os seus respectivos constructos ou VL (HAIR et al., 2014). Assim, quando as AVEs 
são maiores que 0,50, admite-se que o modelo converge a um resultado satisfatório (Fornell \& Larcker, 1981). A análise da Tabela 1 mostra que apenas o constructo norma subjetiva apresenta um valor próximo de 0,50 . Ressalta-se que o construto Informação não apresenta $\mathrm{R}^{2}$, por ser uma variável independente.

Apesar dos valores estarem de acordo com o recomendado pela literatura, optou-se por eliminar as variáveis com cargas fatoriais (correlações) de menor valor, em função da discrepância entre as cargas. Como se observa na Figura 2, as variáveis "NSU_4" (A opinião dos meus amigos pode influenciar minha decisão de me cadastrar como doador de medula óssea) e "NSU_5" (A opinião dos meus familiares influencia minha decisão de realizar o cadastro como doador de medula óssea) possuem cargas inferiores a 0,1, de maneira oposta às demais variáveis, que possuem cargas superiores a 0,9.

Figura 2 - Modelo antes da retirada de variáveis

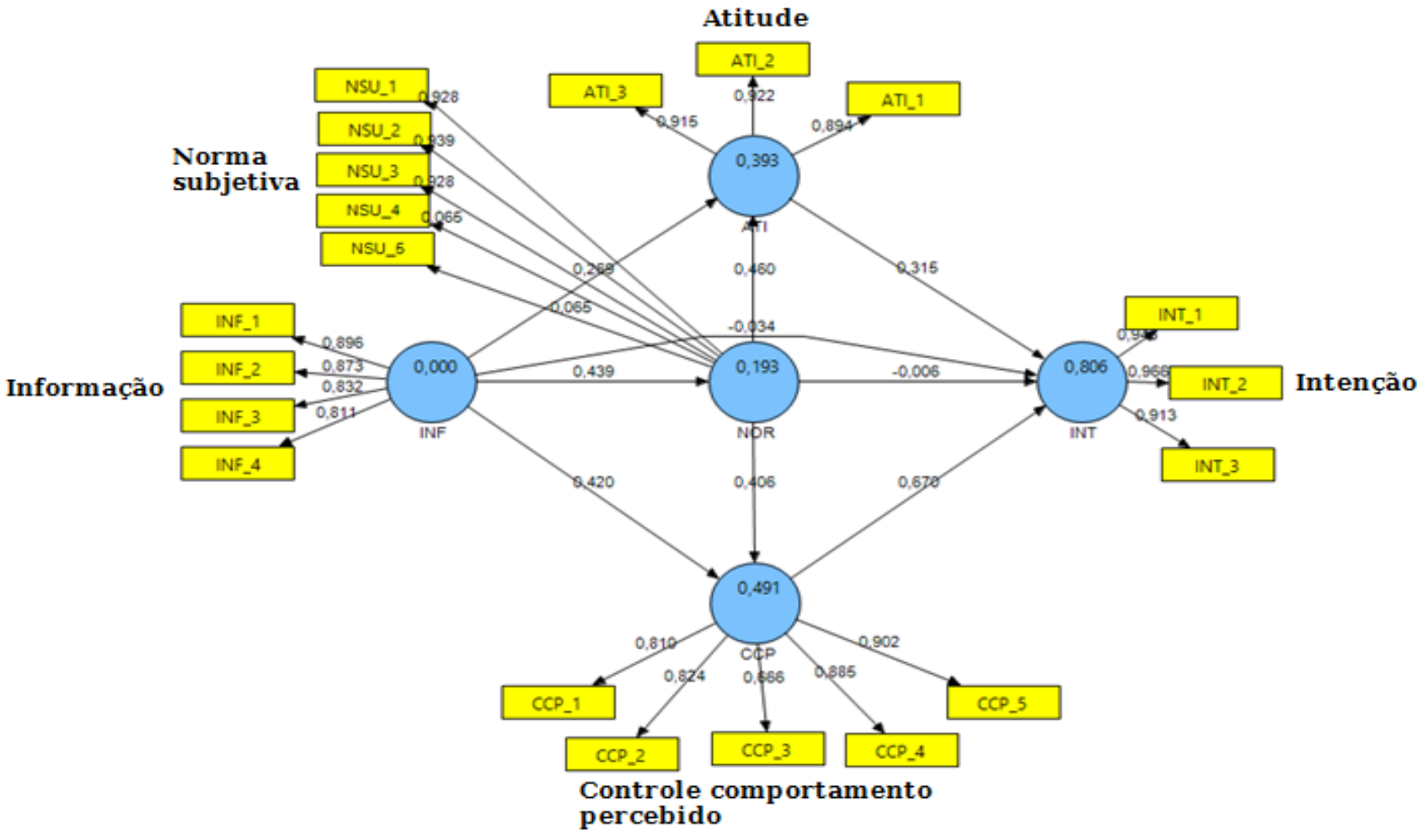

Fonte: Elaborado pelos autores (2018).

Após a eliminação das duas variáveis supracitadas, conseguiu-se obter valores para todas as AVEs acima de 0,60. A Tabela 2 mostra os novos valores da qualidade de ajuste.

Tabela 2 - Valores da qualidade de ajuste do modelo MEE depois da retirada de variáveis

\begin{tabular}{ccccc}
\hline Construto & AVE & CC & $\mathbf{R}^{\mathbf{2}}$ & $\boldsymbol{\alpha}$ \\
\hline ATI & 0,8285 & 0,9354 & 0,3928 & 0,8965 \\
CCP & 0,6750 & 0,9113 & 0,4907 & 0,8769 \\
INF & 0,7288 & 0,9148 & & 0,8756 \\
INT & 0,8881 & 0,9597 & 0,8059 & 0,9368 \\
NOR & 0,8755 & 0,7820 & 0,1928 & 0,7654 \\
\hline
\end{tabular}

Fonte: Elaborado pelos autores (2018).

Depois de garantir a Validade Convergente, a etapa seguinte é a observação dos valores da Consistência interna (alfa de Cronbach, $\alpha$ ) e Confiabilidade Composta (CC). Nos dois casos, tanto AC como CC, são usados para avaliar se as respostas - em seu conjunto - são confiáveis. Valores do AC acima de 0,60 são considerados adequados em pesquisas exploratórias e valores entre 0,70 e 0,90 do CC são considerados satisfatórios (Hair et al., 2014).

A terceira etapa é a avaliação da validade discriminante do MEE, que é entendida como um indicador de que os constructos ou variáveis latentes são independentes um dos outros. Optou-se por 
observar as cargas cruzadas (Cross Loading), que são os indicadores com cargas fatoriais mais altas nos seus respectivos constructos do que em outras (Chin, 1998).

Tabela 3 - Valores das cargas cruzadas

\begin{tabular}{cccccc}
\hline & ATI & CCP & INF & INT & NOR \\
\hline ATI_1 & 0,893933 & 0,658843 & 0,444459 & 0,671812 & 0,501987 \\
ATI_2 & 0,921999 & 0,629210 & 0,399283 & 0,691605 & 0,532324 \\
ATI_3 & 0,914647 & 0,662155 & 0,443035 & 0,746467 & 0,523442 \\
\hline CCP_1 & 0,566220 & 0,809653 & 0,546295 & 0,694200 & 0,544030 \\
CCP_2 & 0,685357 & 0,824058 & 0,449812 & 0,771341 & 0,458268 \\
CCP_3 & 0,474083 & 0,666278 & 0,451598 & 0,491335 & 0,357231 \\
CCP_4 & 0,539303 & 0,885240 & 0,541115 & 0,681878 & 0,485643 \\
CCP_5 & 0,643289 & 0,901719 & 0,475825 & 0,781302 & 0,506643 \\
\hline INF_1 & 0,380932 & 0,522760 & 0,896171 & 0,421782 & 0,330212 \\
INF_2 & 0,408242 & 0,585635 & 0,873013 & 0,483981 & 0,372951 \\
INF_3 & 0,460203 & 0,478236 & 0,832507 & 0,462852 & 0,372294 \\
INF_4 & 0,353000 & 0,444694 & 0,810571 & 0,370491 & 0,369586 \\
\hline INT_1 & 0,722490 & 0,863953 & 0,550038 & 0,947783 & 0,508321 \\
INT_2 & 0,757756 & 0,831898 & 0,482341 & 0,966243 & 0,519505 \\
INT_3 & 0,706617 & 0,762665 & 0,411537 & 0,912502 & 0,505806 \\
\hline NSU_1 & 0,528629 & 0,519303 & 0,404838 & 0,508493 & 0,930309 \\
NSU_2 & 0,549147 & 0,545443 & 0,386477 & 0,509580 & 0,944246 \\
NSU_3 & 0,523740 & 0,554944 & 0,397146 & 0,504140 & 0,932479 \\
\hline
\end{tabular}

Fonte: Elaborado pelos autores (2018).

Ao analisar a Tabela 3, percebe-se que as cargas fatoriais das VOs nos constructos originais são sempre maiores que em outros, sendo constatado que o modelo tem validade discriminante pelo critério de Chin (1998). Em relação à análise do modelo estrutural e ao teste de hipóteses, os coeficientes de regressão padronizados expostos na Figura 3 indicam quanto cada construto afeta as variáveis latentes, quando estas aumentam em uma unidade.

Figura 3 - Modelo ajustado

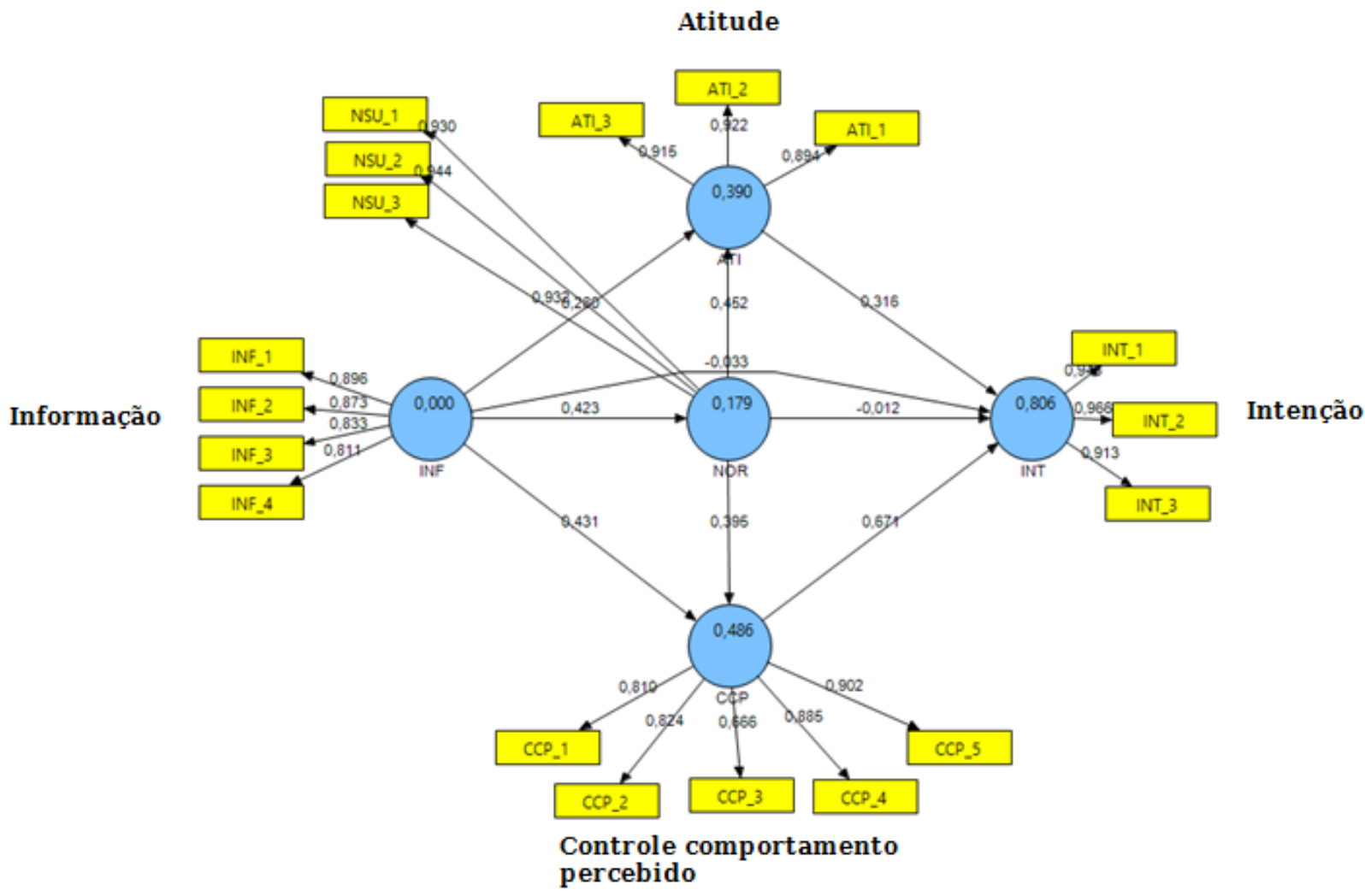

Fonte: Elaborado pelos autores (2018). 
Também é possível verificar os coeficientes de regressão associados a cada uma das variáveis observadas (Informação, Norma Subjetiva, Controle Comportamental Percebido e Atitude) e o quanto elas impactam na variável latente Intenção.

O Controle Comportamental Percebido (CCP) possui o maior coeficiente de regressão $(0,671)$ com a variável Intenção (INT), sendo assim, a variável que mais contribui para explicar a intenção é variável CCP. Por sua vez, a variável Norma Subjetiva (NOR) possui 0,012 de coeficiente de regressão, a variável Atitude (ATI) apresentou 0,316 e a variável Informação (INF) apresentou 0,033 de coeficiente de regressão com a variável Intenção.

Na Figura 2, também podem ser observados os valores dos coeficientes de determinação da variância $\left(\mathrm{R}^{2}\right)$ das variáveis dependentes: Atitude, Norma Subjetiva, Controle Comportamental Percebido e Intenção. Esses coeficientes indicam o percentual de variância da variável dependente, que é explicado pelas variáveis independentes. Os valores de $\mathrm{R}^{2}$ obtidos estão no interior dos círculos que representam essas variáveis. No caso da variável Intenção, o valor do coeficiente de determinação da variância $\left(R^{2}\right)$ obtido foi de 0,806 , evidenciando que $80,6 \%$ de variância desta variável é explicada pelas demais variáveis.

Para a validação do modelo estrutural, foi utilizado o algoritmo de Bootstrapping (amostragem aleatória) do software SmartPLS 2.0M3, com o parâmetro 1000 para o número de casos e amostras. Esse procedimento teve como objetivo realizar 1000 simulações com o conjunto de dados para a obtenção dos resultados do teste da distribuição t de Student e dos erros padrão.

Os resultados do teste $t$ dependem do número de questionários respondidos. Para uma amostra de 335 respondentes, o valor da distribuição t de Student é 1,96, para um intervalo de confiança de 95\% e significância de 0,05. 0 teste $t$ de Student serve para testar a hipótese de que os coeficientes de correlação/regressão possam ser iguais a zero. Caso o resultado do teste $t$ de Student seja igual ou superior a 1,96, a hipótese nula é rejeitada, ou seja, a correlação é significante (HAIR et al., 2014). Diante dos resultados, verificou-se, que somente para a hipótese H5, a hipótese nula não foi rejeitada, sendo assim, a norma subjetiva não tem impacto significante sobre a intenção. Nos demais casos, os valores do teste foram superiores a 2 , indicando que as demais variáveis influenciam na intenção.

Por fim, são avaliados os valores de dois indicadores de qualidade de ajuste do modelo: Relevância/Validade Preditiva $\left(\mathrm{Q}^{2}\right)$ ou indicador de Stone-Geisser e Tamanho do efeito $\left(\mathrm{f}^{2}\right)$ ou Indicador de Cohen. O primeiro $\left(\mathrm{Q}^{2}\right)$ avalia o quanto o modelo se aproxima do que se esperava dele (qualidade da predição do modelo ou acurácia do modelo ajustado). Como critério de avaliação devem ser obtidos valores maiores que zero (HAIR et al., 2014). Um modelo perfeito teria $Q^{2}=1$, ou seja, mostraria que o modelo reflete a realidade - sem erros.

Já o segundo ( $\mathrm{f}^{2}$ ) é obtido pela inclusão e exclusão ( $\mathrm{um}$ a um) de constructos ao modelo. Com isso, avalia-se quanto cada constructo é "útil" para o ajuste do modelo. Valores de 0,02, 0,15 e 0,35 são considerados pequenos, médios e grandes, respectivamente (HAIR et al., 2014). $0 \mathrm{f}^{2}$ também pode ser obtido pela razão entre a parte explicada pelo modelo e a parte não explicada $\left(f^{2}=R^{2} /\left(1-R^{2}\right)\right.$. Tanto um como o outro são obtidos pelo uso do módulo Blindfolding no SmartPLS. Os valores de $Q^{2}$ são obtidos pela leitura da redundância geral do modelo e $\mathrm{f}^{2}$ pela leitura das comunalidades (Tabela 4).

Tabela 4 - Indicadores da qualidade do ajuste do modelo

\begin{tabular}{ccc}
\hline & CV Red $\left(\mathbf{Q}^{2}\right)$ & CV com $\left(\mathbf{f}^{\mathbf{2}}\right)$ \\
\hline ATI & 0,3024 & 0,6188 \\
CCP & 0,3113 & 0,5105 \\
INF & 0,5352 & 0,5352 \\
INT & 0,7012 & 0,7246 \\
NOR & 0,1461 & 0,7010 \\
Valores de & $\mathbb{Q} 2>0$ & $0,02,0,15$ e 0,35 são considerados \\
Referência & pequenos, médios e grandes \\
\hline
\end{tabular}

Fonte: Elaborado pelos autores (2018).

A interpretação da Tabela 4 mostra que tanto os valores de $\mathrm{Q}^{2}$ como de $\mathrm{f}^{2}$ indicam que o modelo tem acurácia e que os constructos são importantes para o ajuste geral do modelo. A análise de equações estruturais utilizada nesta pesquisa indicou que, para a amostra utilizada, as relações hipotetizadas nas hipóteses H1, H2, H3, H4, H6 e H7 não foram rejeitadas. Dessa forma, somente a hipótese H5 foi rejeitada, como se observa na Tabela 5. 
Tabela 5 - Resultados das análises das hipóteses

\begin{tabular}{cccc}
\hline Hipótese & Representação & $\begin{array}{c}\text { Valor t do } \\
\text { Bootstraping* }\end{array}$ & Situação \\
\hline H1 & INF ---> ATI & 2,3466 & Não Rejeitada \\
H2 & INF ---> NOR & 3,1783 & Não Rejeitada \\
H3 & INF ---> CCP & 5,2391 & Não Rejeitada \\
H4 & ATI ---> INT & 3,4322 & Não Rejeitada \\
H5 & NOR ---> INT & 0,0721 & Rejeitada \\
H6 & CCP---> INT & 4,0967 & Não Rejeitada \\
H7 & INF---> INT & 2,2102 & Não Rejeitada \\
\hline
\end{tabular}

* A extração do SmartPLS não apresenta valores de p, porém a distribuição dos coeficientes extraídos nas 1000 reamostragens demandadas é próxima da distribuição t padrão, de modo que o valor de 1,96 é a referência de refutação ou não das hipóteses de nulidade do coeficiente beta.

Fonte: Elaborado pelos autores (2018).

Os elementos resultantes do modelo obtido pela MEE mostraram-se independentes entre si, visto que não se verificou a presença de covariâncias significativas entre os mesmos.

\section{Implicações para a Teoria e Prática}

Como esperado na hipótese H1, as pessoas que possuem informações sobre o processo de doação de órgãos esboçam uma atitude positiva para a realização do cadastro no REDOME. Resultados similares foram evidenciados nas hipóteses $\mathrm{H} 2$ e H3, onde ocorreu a não rejeição das hipóteses relativas à norma subjetiva e ao controle comportamental percebido.

Com relação à hipótese H4, verifica-se que a atitude influencia na intenção comportamental das pessoas para realizar o cadastro, contrariando os achados de Barboza e Costa (2014), que identificaram uma fraca influência da atitude na intenção do indivíduo em doar sangue. Resultados similares foram encontrados em estudos que utilizaram a mesma teoria para investigar outras temáticas (Beerli-Palacio \& Martín-Santana Barboza, 2009; Rezende et al., 2015).

Referente à hipótese H5, o resultado da Tabela 5 revela que a norma subjetiva não possui relação significativa com a intenção para realizar cadastro para o processo de doação, ou seja, dentre os investigados nesta pesquisa, a pressão social não influencia no processo de realizar cadastro para ser um doador de medula.

Em relação às hipóteses H6 e H7, verificou-se que as mesmas não foram rejeitadas, reforçando a importância da variável de informação sobre a intenção de se cadastrar com doador de medula, assim como Beerli-Palacio e Martín-Santana (2009) afirmaram. Entretanto, este resultado difere dos achados de Barboza e Costa (2014), que não reconheceram a disponibilidade de informação como um dos fatores influentes na predisposição do sujeito em doar sangue. Dessa forma, esta pesquisa complementa os estudos que tratam de doação de órgãos desenvolvidos nacional e internacionalmente, a partir da utilização de uma teoria sólida sobre o comportamento das pessoas.

Ademais, os resultados sugerem que, para realizar o cadastro no banco de doação de medula óssea, é essencial que o indivíduo perceba que a sua ação é efetiva e pode ajudar diretamente a vida de outras pessoas. Dessa forma, com base no modelo ajustado, as campanhas de marketing social devem, além de informar os potenciais doadores sobre o processo de doação, reforçar que esta ação é essencial para a saúde dos pacientes que precisam do transplante.

Em consonância com os achados de Rezende et al. (2015), os resultados da pesquisa apontam a necessidade de maior divulgação e esforços mais intensivos na educação do cidadão poderiam compor estratégias de marketing social mais assertivas. As campanhas de marketing social devem, além de informar os potenciais doadores sobre os benefícios da realização do cadastro, detalhar os requisitos e etapas necessárias para efetivar o cadastro no REDOME, o que pode ser feito por meio de mídias sociais e em campanhas associadas às coletas externas de doação de sangue (postos de coleta itinerantes) realizadas em universidades, praças, empresas. Tais esclarecimentos poderiam ser repassados antes, durante e após a coleta de sangue, uma vez que doadores de sangue são indivíduos com potencial de realizar o cadastro para doação de medula óssea (Morais \& Morais, 2012).

\section{Conclusões}

Os estudos de doação de órgãos e de marketing convergem na medida em que este último pode 
contribuir para o planejamento de campanhas de instituições públicas com a finalidade de promover mudanças de comportamentos coletivos. Desse modo, este estudo visou contribuir nesse contexto, trazendo uma investigação dos fatores que influenciam a intenção dos indivíduos a doarem medula óssea, em uma perspectiva típica das análises de marketing.

Para alcançar tal objetivo, foi realizado um levantamento empírico, onde os dados foram obtidos a partir da aplicação de um questionário e a análise feita por meio de uma abordagem quantitativa. Os resultados indicaram que a atitude, o controle comportamental percebido e as informações que os indivíduos possuem exercem influência sobre a intenção comportamental da pessoa em realizar o cadastro para doação de medula. Entretanto, a norma subjetiva não possui relação significativa com a intenção de realizar cadastro.

Este estudo contribuiu para o desenvolvimento do campo de estudos do marketing social, na medida em que se elaborou um modelo que pode subsidiar a elaboração de ações de marketing para a doação de medulo óssea no Brasil, ao mesmo tempo que possibilitou compreender com maior profundidade os fatores motivacionais que influenciam as pessoas a se cadastrarem no REDOME.

Uma das limitações deste estudo trata do tamanho do universo da pesquisa que não foi determinado. A amostra é não probabilística e acessada por conveniência. Desse modo, recomendam-se estudos que prezem pelo emprego de amostras mais significativas e rigorosas. Além disso, sugere-se a criação de escalas que mensurem os antecedentes da doação órgãos e sangue adaptado a realidade brasileira, considerando a Teoria do Comportamento Planejado e variáveis de outros estudos.

Ademais, é sugerida a realização de estudos com pessoas que já realizaram o cadastro para doação de medula óssea. As motivações e dificuldades enfrentadas para a adoção deste comportamento podem ser analisadas. Outra possibilidade é a condução de estudos com profissionais da saúde que trabalham com a doação de órgãos ou com familiares de pacientes que doaram ou receberam órgãos. Estudo similar foi desenvolvido por Santos e Massarollo (2005), embora a ênfase tenha sido dada no processo de doação de órgãos em si, e não nos aspectos motivacionais.

\section{Referências}

Associação Brasileira de Transplantes de Órgãos [ABTO]. (2018). Orientações sobre doação de órgãos. Brasília: ABTO.

Ajzen, I. (1988). Attitudes, personality and behavior. Chicago: Dorsey Press.

Ajzen, I. (1991). The theory of planned behavior. organizational behavior and human. Decision Processes, $50,179-211$.

Ajzen, I. (2002). Residual Effects of Past on Later Behavior: Habitual and Reasoned Action Perspectives. Personality and Social Psychology Review, 6 (2), 107-122.

Ajzen, I. \& Fishbein, M. (1970). The prediction of behavior from attitudinal and normative variables. Journal of Experimental Social Psychology, 6, 466-487.

Barboza, S. \& Costa, F. (2014). Marketing social para doação de sangue: análise da predisposição de novos doadores. Caderno de Saúde Pública, 30(7).

Beerli-Palacio, A. \& Martín-Santana, J. D. (2009). Model explaining the predisposition to donate blood from the social marketing perspective. International Journal of Nonprofit and Voluntary Sector Marketing, 14, 205-214.

Brandão, W. (2016). Consumo saudável: uma análise do comportamento do consumidor no contexto dos alimentos orgânicos. Dissertação de Mestrado, Universidade Federal da Paraíba, João Pessoa, PB, Brasil. Chin, W. W. (1998). The partial least squares approach for structural equation modeling. In Marcoulides, G.A. (Ed.). Modern methods for business research. London: Lawrence Erlbaum Associates, 295- 336.

Conner, M. \& Mcmillan, B. (1999). Interaction effects in the theory of planned behaviour: studying cannabis use. British Journal of Social Psychology, 38.

Doró, M. P., \& Pasquini, R. (2000). Transplante de Medula Óssea: uma confluência biopsicossocial. Interação, 4(1),39-60.

Faria, M. A. (2015). Eterna criança e as barreiras do ter: consumo de pessoas com Síndrome de Down e suas famílias. 2015. Tese de Doutorado, Universidade Federal do Rio de Janeiro, Rio de Janeiro, RJ, Brasil. Fishbein, M. \& Ajzen, I. (1975). Belief, Attitude, Intention and Behavior: An Introduction to Theory and Research. Reading, MA: Addison-Wesley.

Fornell, C. \& Larcker, D.F. (1981). Evaluating structural equation models with unobservable variables and measurement error. Journal of Marketing Research, 18(1), 39-50. 
Goecking, O. H. P. (2006). Comparação de Teorias da Ação para explicar intenções comportamentais e comportamentos reais correspondentes. Dissertação de Mestrado, Universidade Federal de Minas Gerais, Belo Horizonte, MG, Brasil.

Hair, J., Hult, T.M., Ringle, C.M, \& Sarstedt, M. (2014). A Primer on Partial Least Squares Structural Equation Modeling (PLS-SEM). Los Angeles: SAGE.

Hoppe, A., Barcellos, M. D., Vieira, L. M., \& Matos, C. A. (2012). Comportamento do consumidor de produtos orgânicos: uma aplicação da Teoria do Comportamento Planejado. BASE - Revista de Administração e Contabilidade da UNISINOS, 9(2), 174-188.

Instituto Nacional de Câncer [INCA]. (2012). Cartilha sobre doação de medula óssea. Brasília: INCA.

Lei $n^{o}$ 9.434, de 4 de fevereiro de 1997. Dispõe sobre a remoção de órgãos, tecidos e partes do corpo humano para fins de transplante e tratamento e dá outras providências. Recuperado em 11 abril, 2018, de http://www.planalto.gov.br/CCIVIL_03/Leis/L9434.htm

Lemmens, K.P., Abraham, C., Ruiter, R. A. C., Veldhuizen, I.J.T., Dehing, C. J. G., \& Bos, A. E. R. (2009). Modelling antecedents of blood donation motivation among non-donors of varying age and education. Br J Psychol, 100, 71-90.

Malhotra, N. (2001). Pesquisa de Marketing. 3. ed. Porto Alegre: Bookman.

Matos, E. B. (2013). Comportamento e meio ambiente - Um estudo comportamental da intenção de não uso das sacolinhas de plástico. Revista de Gestão, 20, (2), 217-232.

Matos, E. B., Veiga, R. T., \& Lima, I. L. (2008). A Decisão na Teoria do Comportamento Planejado: um estudo da intenção de uso de condons por adolescentes. Anais do Encontro Nacional da Associação Nacional de Pós-Graduação e Pesquisa em Administração, Rio de Janeiro, RJ, Brasil, 27.

Morais, T. \& Morais, M. (2012). Doação de órgãos: é preciso educar para avançar. Saúde em Debate, 36(95), 633-639.

Moutinho, K. \& Roazzi, A. (2010). As teorias da ação racional e da ação planejada: Relações entre intenções e comportamentos. Avaliação Psicológica, 9(2) 279-287.

Oliveira-Cardoso, E., Santos, M. A., Mastropietro, A. P., \& Voltarelli, J. C. (2010). Doação de medula óssea na perspectiva de irmãos doadores. Revista Latino-Americana de Enfermagem, 18(5), 911-918.

Pereira, J., Sousa, C. V., Matos, E. B., Rezende, L. B., Bueno, N. X., \& Dias, A. M.. (2016). To donate or not donate, that is the question: an analysis of the critical factors of blood donation. Ciência \& Saúde Coletiva, 21(8), 2475-2484.

Rezende, L. et al. (2015). Doação de Órgãos no Brasil: Uma Análise das Campanhas Governamentais sob a Perspectiva do Marketing. Revista Brasileira de Marketing - ReMark, 14(3).

Ringle, C., Silva, D., \& Bido, D. (2014). Modelagem de Equações Estruturais com Utilização do Smartpls. Revista Brasileira de Marketing - ReMark, 13(2).

Santos, M. J., \& Massarollo, M. C. (2005). Processo de doação de órgãos: percepção de familiares de doadores cadáveres. Latino-am Enfermagem, 13(3), 382-387.

Shaz, B.H., Demmons, D.G., Crittenden, C. P., Carnevale, C. V., Lee M., \& Burnett, M. (2009). Motivators and barriers to blood donation in African American college students. Transfus Apher Sci, 41, 191-197.

Sheth, J. N. (1974). Consumer behavior: theory and application. Boston: Allyn \& Bacon.

Silva, S. L., Oliveira, I. L. F., Pego, Z. O., Pereira, J. R., \& Sousa, C. V. (2016). Condicionantes da Motivação para a Doação de Órgãos: uma Análise à Luz do Marketing Social. Teoria e Prática em Administração, 6(1), 69-96.

Sousa, A. M. R., Rabêlo Neto, A., \& Fontenele, R. E. S. (2013). Determinantes da intenção da escolha do ensino superior privado: uma perspectiva da Teoria do Comportamento Planejado. Revista Eletrônica de Ciência Administrativa, 12(3), 366-377.

Veiga, R. T., Santos, D. O., \& Lacerda, T. S. (2006). Antecedentes da intenção de consumo de cosméticos ecológicos. Revista Eletrônica de Ciência Administrativa, 5(2), 1-15. 